\title{
Empty shelves
}

\section{How your academic library can address food insecurity}

$\mathbf{R}$ esearchers have only recently begun looking at food insecurity on college campuses. Food insecurity is characterized by the U.S. Department of Agriculture (USDA) as limited or uncertain access to nutritionally adequate and safe foods or the ability to acquire acceptable foods in socially acceptable ways due to limited financial resources. ${ }^{1}$ Harmony Reppond illustrates this point when writing, "food insecurity for college students can mean running out of food between paychecks, attending campus events in search of food, reducing food intake, purchasing minimally nutritious food that costs less, skipping meals, and deciding between paying for textbooks or food." ${ }^{2}$ Food insecurity is often an invisible condition because of the stigma associated with hunger and poverty. However, the extent and severity of food insecurity on college campuses is alarming. The U.S. Government Accountability Office (GAO) conducted a literature review and found that college student food insecurity rates exceeded $30 \%$ in the majority of published studies. ${ }^{3}$ The Hope Center at Temple University conducts an annual survey on student basic needs, which originally covered food and housing insecurity, and has since been expanded to include transportation, childcare, stress, and mental health. Over the last five years this survey has been completed by more than 330,000 students attending 411 colleges and universities, and the Hope Center has found that on average over the last five years 39\% of respondents reported being food insecure in the prior 30 days. ${ }^{4}$ The rise of student food insecurity is linked to a decrease in public funding for higher education, which in turn has caused a steep increase in tuition rates, combined with more low-income students entering college. 5

Indeed, student food insecurity is experienced at higher rates by traditionally underrepresented groups, including first-generation college students, Black and Indigenous people, single parents, people with disabilities, nonbinary and trans identifying individuals, former foster youth, and those who are presently unhoused or at risk of homelessness. ${ }^{6}$ While food insecurity is arguably prevalent at every college and university in the United States, it is higher for students attending public universities and two-year colleges. ${ }^{7}$ Students experiencing food insecurity are overwhelmingly part of the labor force, with many of the most food insecure working more hours than their peers. ${ }^{8}$

This grim picture is being exacerbated by the economic devastation cause by the COVID-19 pandemic. As unemployment rises, demand at food banks has increased by as much as $600 \%$ and applications for the Supplemental Nutrition Assistance Program (SNAP, formerly known as food stamps),

\footnotetext{
Lana Mariko Wood is health sciences and scholarly communications librarian and a founding advisory board member of Pioneers for HOPE at California State University-East Bay, email: Iana.wood@ csueastbay.edu
}

(c) 2020 Lana Mariko Wood 
have more than doubled in most states. ${ }^{9}$ Food banks are struggling to keep up with this increased demand, and many states are cash-strapped to fund hunger-relief programs. ${ }^{10}$ As our academic libraries begin reopening across the country, we must prepare to welcome more students, and potentially furloughed faculty and staff, who are struggling to have their basic needs met.

\section{Our role}

Academic libraries value and work towards student success and equity, yet food insecurity often undermines our progress. ${ }^{11}$ Food insecurity affects students' academic success, including college completion, a cademic performance, class attendance, and concentration in class. ${ }^{12}$ Consistent hunger can cause students to drop out or take on additional loans to cover the cost of food and other basic necessities. ${ }^{13}$

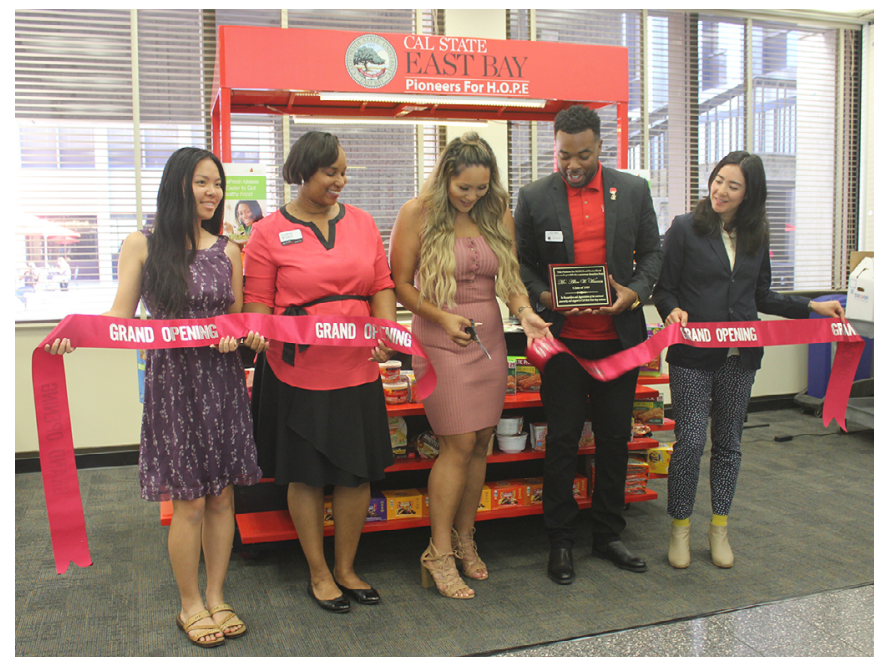

Cal State-East Bay's Pioneers for HOPE food pantry library kiosk's grand opening celebration. The author is seen on the far right. Photo courtesy of Diana Wakimoto.

The stress

caused by food insecurity negatively affects students' mental and physical health, leading to long-term health consequences such as depression, hopelessness, isolation, and embarrassment. ${ }^{14}$ Food insecurity is inextricable from equity because of its detrimental effects and disproportionate burden on traditionally underrepresented groups in higher education.

Academic libraries are uniquely positioned to address food insecurity. We are experts at navigating information, resources, and systems. We have long been in the business of distributing materials, and continually find innovative and effective ways to do so. ture of care across the campus.

\section{Food pantries}

We are privacy experts and have stated values around equity and inclusion. We support the whole student, both individually and in collaboration with other campus units, and are skilled in outreach and programming. Our work and expertise positions us to be leaders in addressing food insecurity on our campuses.

\section{Addressing student food insecurity}

Pioneers for HOPE is an intervention program that focuses on addressing students' basic needs at California State UniversityEast Bay (Cal State-East Bay). ${ }^{15}$ It was founded in August, 2016, in response to the find-

ings from a report looking at student housing and food insecurity for the entire California State University system. ${ }^{16}$ Pioneers for HOPE is led by Student Health and C o un s e ling Services, and the Advisory Board has representatives from across Cal State-East Bay, including the library. One of Pioneers for HOPE's guiding principles is the importance of maintaining dignity for those seeking basic needs services, including reducing stigma, providing privacy, and normalizing and creating a cul-

As of September, 2018, more than 650 U.S. colleges report having a food pantry on campus that provides free food to college students in need. ${ }^{17}$ While it is unclear where these pantries are physically located on the 
campus, libraries provide an ideal location to house campus food pantries because of the library's expansive hours and student traffic. At Cal State-East Bay, the library offers an after-hours kiosk where students can pick up healthy snacks and beverages in the evening after the primary pantry, which is stocked with grocery staples, has closed. This kiosk is available to anyone without needing to prove their eligibility in order to reduce stigma in using the service, which also serves as a jumping off point for connecting students in need with additional basic needs services offered through Pioneers for HOPE.

Library food pantries are not one-sizefits-all. Other examples include housing the primary pantry in the library, partnering with the campus pantry to discretely offer prepackaged bags of food that students can claim at the circulation desk, and creating a DIY food pantry, where the campus community is encouraged to take what they need and give what they can. ${ }^{18}$ Even if there is not enough space in the library for a permanent pantry, it may be possible for your library or campus to have a mobile or pop-up pantry, where students can still access food on-site, such as drive-through services to pick up pre-packed grocery bags. Organizations like the College \& University Food Bank Alliance (CUFBA) provide a "Getting Started Toolkit," along with other guidelines and best practices for improving outreach and pantry success. ${ }^{19}$

\section{SNAP application assistance}

A report issued by GAO estimates that $57 \%$ of students at risk for food insecurity and eligible for SNAP do not collect those benefits, and part of the reason for these low levels of usage may be because there is insufficient clarity about student eligibility for SNAP. ${ }^{20}$ At Cal State-East Bay we have reframed SNAP as "food aid," and communicate to students that if they are eligible for financial aid, they are most likely eligible for food aid. This reframing has helped to increase SNAP enrollment on our cam- pus and reduce the stigma in using SNAP, since so many students receive financial aid and know others who do as well.

The complexity of SNAP eligibility provides an opportunity for libraries to help students navigate this process, as well as help to address existing misinformation and rumors about how SNAP benefits may affect student's financial aid, work study allotment, and immigration status. At Cal State-East Bay, work-study students have been trained to assist students in signing up for "food aid." Allowing students to work with their peers creates a greater sense of community, particularly since many of the work-study students who help with SNAP applications are also eligible for the program. The majority of in-person SNAP enrollment takes place at the library kiosk, since it is open in the evening when students tend to have more availability.

\section{Community partnerships}

Cal State-East Bay partners with a number of community organizations on basic needs initiatives. Some of the groups related to food insecurity include the local food bank ${ }^{21}$ to help stock the pantry; Cooking Matters to help teach students how to make simple, healthy meals on a budget; and CalFresh to provide training on signing students up for SNAP. Student groups may be working on food insecurity already and are excellent to partner with. Associated Students Incorporated at Cal State-East Bay partners with Swipe Out Hunger, which encourages students to donated their unused meal swipes from the dining hall to students in need.

\section{Service navigation}

The Pioneers for HOPE program serves as the primary basic needs insecurity service navigation on campus. However, for those campuses that do not have centralized basic needs services, libraries can create LibGuides with curated information on local food banks, campus pantries, SNAP, and other related services, such as housing and emergency aid. 


\section{Redistributing leftover food}

How many times has your library held an event and overbought food? To help address this, Cal State East-Bay has created a campus-wide alert system, where students opt-in to receive text messages letting them know when there is leftover catered food available anywhere on campus. Students are alerted in real time about what type of food is available, where to find it, and when it will be cleared away. Campuses without texting services can consider using social media, such as Twitter, to alert students about available food.

\section{Conclusion}

Many college students on your campus are grappling with food insecurity, and this lack of access to healthy food is affecting their studies and ability to thrive. While the number of food insecure students is already high, the global economic impact of the COVID-19 pandemic is making this problem more widespread and urgent. Academic libraries must use our unique skills and position on campus to support all students by taking steps to address food insecurity.

\section{Notes}

1. United States Department of Agriculture, "Measurement," September 4, 2019, https://www.ers.usda.gov/topics/food-nutrition -assistance/food-security-in-the-us/measurement.aspx.

2. Harmony Reppond, "Many College Students Struggle to Have Their Basic Needs Met," The SES Indicator 12, no. 3 (2019), https://www. apa.org/pi/ses/resources/indicator/2019/12 /college-students-needs.

3. United States Government Accountability Office, "Food Insecurity: Better Information Could Help Eligible College Students Access Federal Food Assistance Benefits" (U. S. Government Accountability Office, January 9, 2019), https://www.gao.gov/products/GAO -19-95. p. 4.

4. Christine Baker-Smith, et al., "\#RealCollege 2020: Five Years of Evidence on Campus
Basic Needs Insecurity" The Hope Center, 2020, https://hope4college.com/wp-content /uploads/2020/02/2019_RealCollege _Survey_Report.pdf.

5. Reppond, "Many College Students Struggle to Have Their Basic Needs Met."

6. United States Government Accountability Office, "Food Insecurity"; Baker-Smith, et al., "\#RealCollege 2020: Five Years of Evidence on Campus Basic Needs Insecurity."

7. Baker-Smith, et al., "\#RealCollege 2020: Five Years of Evidence on Campus Basic Needs Insecurity."

8. Ibid.

9. Li Zhou, "Coronavirus Is Exacerbating America's Hunger Crisis," Vox, May 11, 2020, https://www.vox.com/2020/5/11/21233063 /food-banks-snap-coronavirus.

10. Abby Vesoulis, "It's a Bucket Brigade on a 5-Alarm Fire.' Food Banks Struggle to Keep Up with Skyrocketing Demand," Time, April 24, 2020, https://time.com/5825944/food-banks -coronavirus/.

11. Association of College and Research Libraries, "ACRL Plan for Excellence," November 2019, www.ala.org/acrl /aboutacrl/strategicplan/stratplan.

12. Maya E. Maroto, Anastasia Snelling, and Henry Linck, "Food Insecurity Among Community College Students: Prevalence and Association with Grade Point Average," Community College Journal of Research and Practice 39, no. 6 (2015): 515-26, https://doi.org/10.1080 /10668926.2013.850758; Suzanna M. Martinez, et al., "No Food for Thought: Food Insecurity Is Related to Poor Mental Health and Lower Academic Performance among Students in California's Public University System," Journal of Health Psychology, 2018, 1-10, https://doi. org/10.1177/1359105318783028.

13. Kaya Laterman, "Tuition or Dinner? Nearly Half of College Students Surveyed in a New Report Are Going Hungry," The New York Times, May 2, 2019, sec. New York, https:// www.nytimes.com/2019/05/02/nyregion /hunger-college-food-insecurity.html.

(continues on page 334) 
demic libraries to make timely and critical decisions in support of student online learning. These challenges may present health sciences librarians greater opportunities to promote their value and to become integral to their institutional goals. At the four academic health sciences libraries, transition to online learning and remote work has served as a catalyst for increased access to and use of library online resources by students, faculty, and researchers who are striving to retain normalcy in their daily routine. It is vital for librarians to stay proactive, flexible, and nimble in providing library services and handling library processes, procedures, and policies to meet emerging needs in the rapidly evolving situation. To stay well, productive, and creative, the ability to quickly adapt to new technologies and the new normal is as important as the ability to practice good self-care and to attend to one's own emotional, social, and physical health needs.

("Empty shelves," continues from page 325)

14. Ilana G. Raskind, Regine Haardorfer, and Carla J. Berg, "Food Insecurity, Psychosocial Health, and Academic Performance among College and University Students in Georgia, USA," Public Health Nutrition 22, no. 3 (2019): 47685, https://doi.org/10.1017/S1368980018003439; Erica Reynolds et al., "Prevalence and Correlates of Food Insecurity among Students Attending a Small, Rural Canadian University," Canadian Journal of Dietetic Practice and Research 79, no. 3 (2018): 125-28.

15. California State University, East Bay, "Pioneers for HOPE," 2020, https://www.csueastbay.edu/hope/.

16. Rashida Crutchfield and Jennifer Maguire, "Study Of Student Basic Needs" (California State University Office of the Chancellor, January 2018).

17. United States Government Accountability Office, "Food Insecurity."

18. Emily Udell, "Food for Thought," American Librar-

\section{Notes}

1. Yingting Zhang, "COVID-19 Information Resources," January 31, 2020, https:// libguides.rutgers.edu/covid19_resources/ home.

2. Rutgers New Jersey Medical School. "Center for COVID-19 Response and Pandemic Preparedness: Research Resources," 2020, http://njms.rutgers.edu/research/CCRP2/ ResearchResources.cfm, accessed May 1, 2020.

3. . Jill Wurm and Maria Nuccilli, "COVID-19: Updates from the Library System," March 15, 2020, https://library.wayne.edu/ covid-19/.

4. Ella Hu, "Coronavirus Disease 2019 (COVID-19): General Information," February 28, 2020, https://guides.lib.wayne.edu/ COVID-19.

5. The University of Tennessee Health Science Center Health Sciences Library, "2019 Novel Coronaviru: Resources regarding the 2019 Novel Coronavirus," March, 5, 2020, https://libguides.uthsc.edu/coronavirus/. „ ies Magazine, May 1, 2019, https:// americanlibrariesmagazine.org/2019/05/01/ library-campus-food-insecurity-food-for -thought/; Joe Hardenbrook, "Starting a Food Pantry in an Academic Library," Mr. Library Dude (blog), September 13, 2019, https:// mrlibrarydude.wordpress.com/2019/09/13 /starting-a-food-pantry-in-an-academic -library/.

19. College and University Food Bank Alliance, "Resources," accessed May 26, 2020, https://cufba.org/resources/.

20. United States Government Accountability Office, "Food Insecurity."

21. Many food banks allow for large group volunteering. These are excellent opportunities for team-building, while also making food insecurity more visible. Each year I organize a faculty cohort volunteering session at the local food bank for us to catch up, sort produce, and talk about student basic needs initiatives. $\boldsymbol{z}$ 